\title{
Relationship of Perceived Benefits and Perceived Barriers with Reg- ular Physical Activity Among Employees of Mashhad University of Medical Sciences
}

\begin{abstract}
Background and objective: The development of technology in many developed communities has resulted in sedentary living and the appearance of many noninfectious diseases. In order to solve this problem and change the activity patterns, the factors affecting the physical activity should be clarified. This study tried to determine the benefits and perceived barriers of regular physical activities of the employees.

Materials and methods: In this cross-sectional study, 117 employees of health center in Kalat, in Razavi Khorasan Province in Iran, affiliated with Mashhad University of Medical Sciences (MUMS), were studied in 2012-2013. In order to gather the data, a standard questionnaire of perceived benefits and barriers of physical activity was used. The data were analyzed using SPSS 16.

Results: The average age of the employees were $34.09 \pm 8.08$ years and 66 of them (56.4\%) were female. Overall, $34.2 \%$ of the employees had regular physical activity- $53 \%$ of male and $20 \%$ of female ones. The mean of perceived benefit scores was 100.3. \pm 1.4 and the mean of perceived barrier scores was $25.9 \pm 6.14$. There was a significant relationship between physical activity and the age $(p<0.01)$ as well as the level of education $(p=0.01)$ but the presence or absence of physical activity had no significant relationship with the perceived benefits $(p<0.58)$.

Conclusion: Lack of adequate facilities for physical activities such as being far away, time-consuming and tiring due to exercise were the barriers for doing physical activities and some other factors like being interested in the exercises motivate the employees to do the physical activities.

Keywords: Perceived benefits, Perceived barriers, Physical activity, Health workers, Health centers, Kalat County.

Paper Type: Research Article.
\end{abstract}

- Citation (Vancouver): Vafaee-Najar A, Ebrahimipour H, Behzad F, Tehrani H. Relationship of perceived benefits and perceived barriers with regular physical activity among employees of Mashhad University of Medical Sciences. Iran J Health Educ Health Promot. Spring 2017;5(1):58-64. [Persian]

- Citation (APA): Vafaee-Najar, A., Ebrahimipour, H., Behzad, F., Tehrani, H. (Spring 2017). Relationship of perceived benefits and perceived barriers with regular physical activity among employees of Mashhad University of Medical Sciences. Iranian Journal of Health Education \& Health Promotion., 5(1), 58-64. [Persian]
Ali Vafaee-Najar

Associate Professor, Dept. of Management and Health Economics, School of Health, Social Determinant of Health Research Center, Mashhad University of Medical Sciences, Mashhad, Iran.

Hosein Ebrahimipour

Associate Professor, Dept. of Management and Health Economics, School of Health, Social Determinant of Health Research Center, Mashhad University of Medical Sciences, Mashhad, Iran.

Fatemeh Behzad

MSc in Health Education and Health Promotion, Dept. of Health Education \& Health Promotion, School of Health, Mashhad University of Medical Sciences, Mashhad, Iran.

Hadi Tehrani

* Assistant professor. Dept. of Health Education \& Health Promotion, School of Health, Social Determinant of Health Research Center, Mashhad University of Medical Sciences, Mashhad, Iran. (Corresponding Author) Tehranih@ mums.ac.ir

Received: 19 December 2016

Accepted: 07 April 2017

DOI: 10.18869/acadpub.ihepsaj.5.1.58 


\section{ارتباط فوايد و موانع دركشده با فعاليت بدنى منظم در كارمندان} مركز بهداشت شهرستان كلات

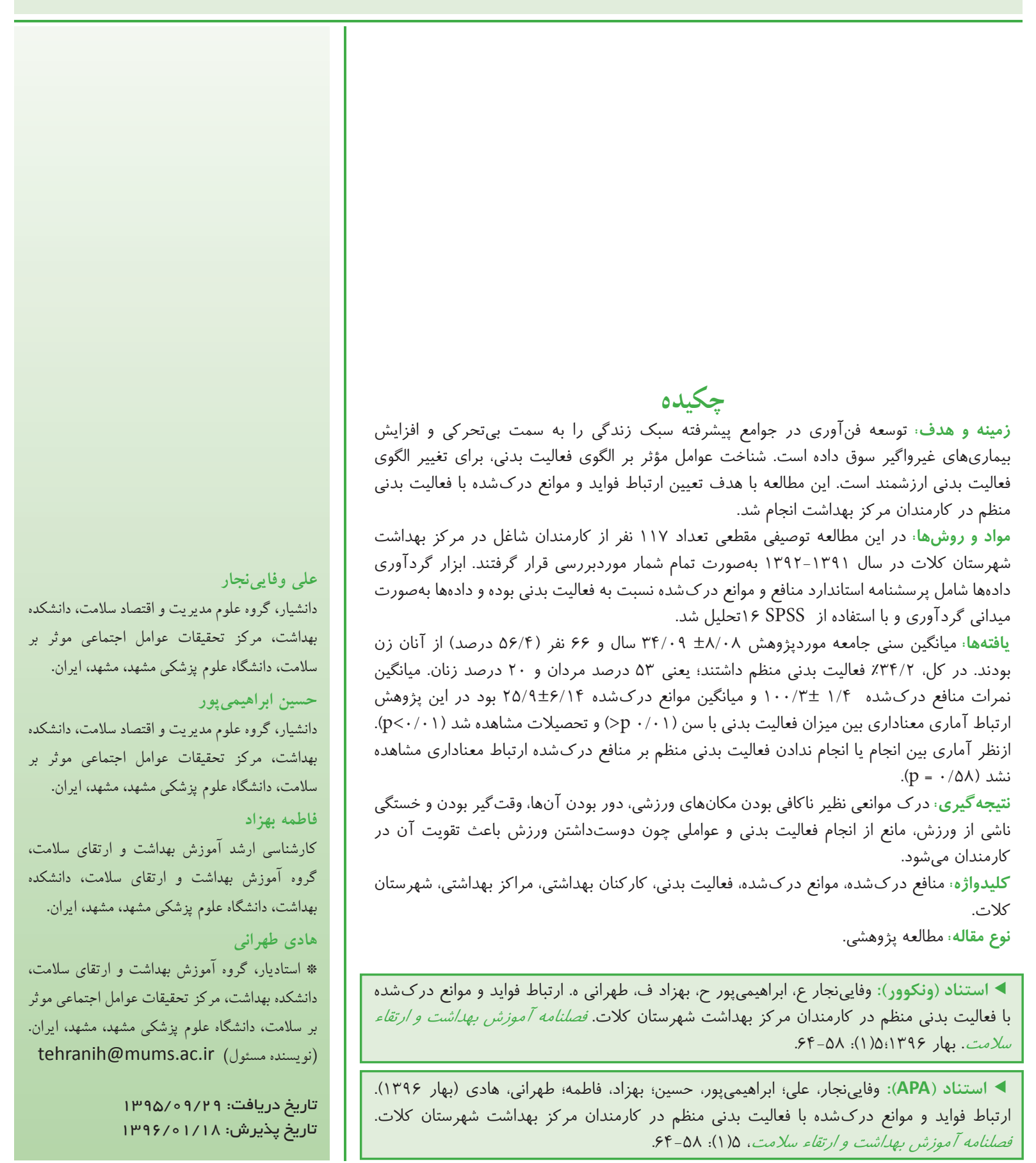


مثبت و منفى هستند كه مىتوانند موجب انجام و يا انجام ندادن مقامه

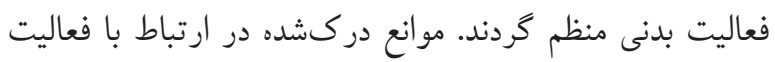

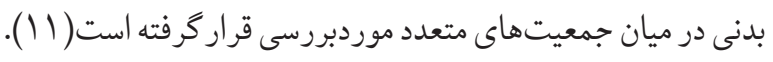

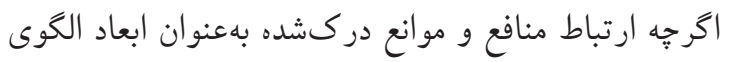

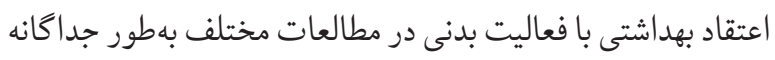

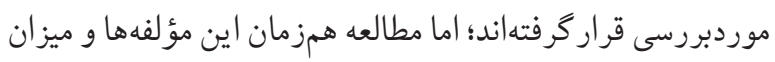

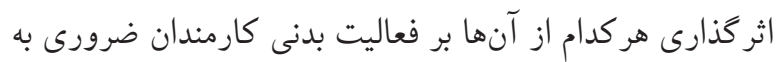

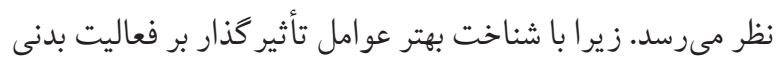

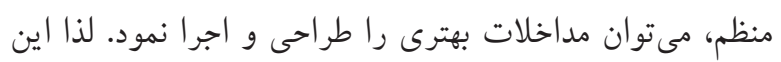

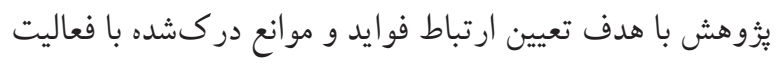
بدنى منظم در كارمندان مركز بهداشت شهرستان كلات در سال

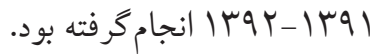

مو اد و روش ها اين بررسى، بخشى از يك مطالعه توصيفى- تحليلى از نوع

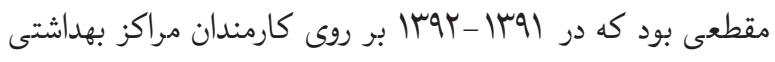
درمانى زير يوشش دانشكاه علوم يزشكى مشهد در شهر كلات انجام شد. در اين مطالعه كليه كارمندان شبكه بهداشت و درمان شهرستان بهصورت تمام شمار موردبررسى قرار گرفتند.

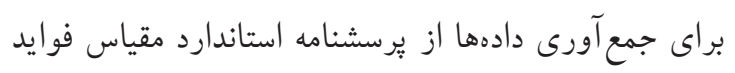

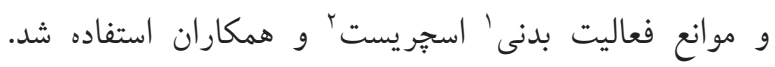

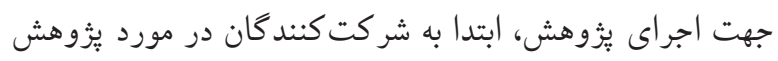

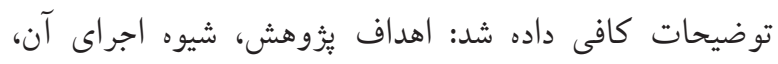

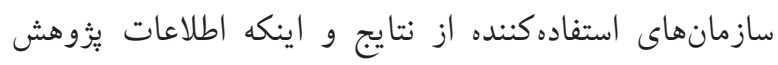
تنها در اختيار يُزوهشكران قرار خواهد كرفت. تمام برسشنامهها

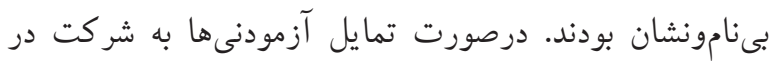
مطالعه وامضاء كردن فرم رضايتنامه، تِرسشنامه در اختيار آنان قرار مى گرفت و توسط خود افر اد تكميل مى شد.

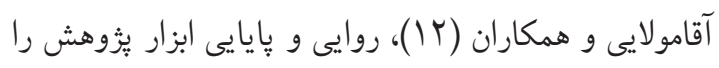

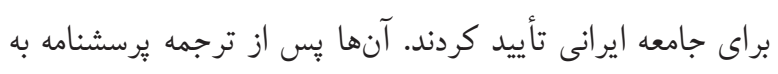

1. Exercise Benefits/Barriers Scale

2. Karen Sechrist

افزايش فعاليت بدنى در گزارش مردم سالم تا سال •r.r. در صدر اولويتهاى بهداشتى قراركرفته است( ا, Y). شواهد متعددى نيز وجود دارد كه انجام فعاليت بدنى منظم منجر به ارتقاء سلامت روان،

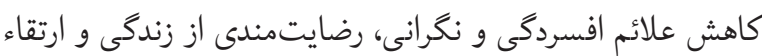

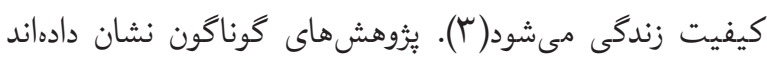
كه عوامل مختلف فردى ازجمله متغيرهاى جمعيتش زئناختى، نكرش، باورهاى فردى و عوامل محيطى و اجتماعى بر انجام

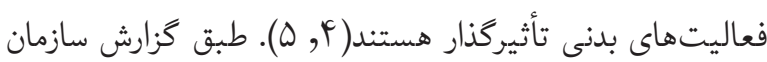

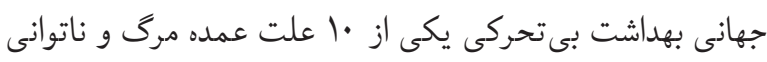

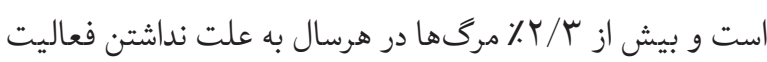

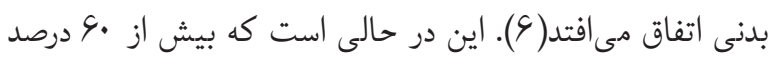

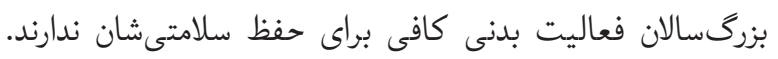

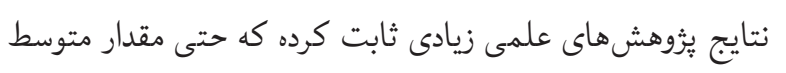

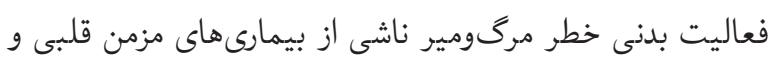

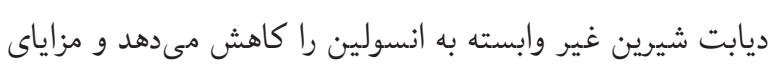

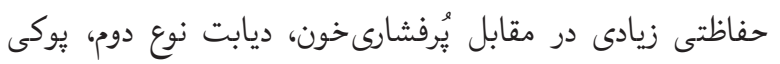

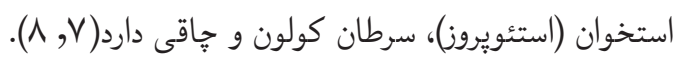
يافتههاى بررسى ملى در بين بزرخسالان ايرانى نشان

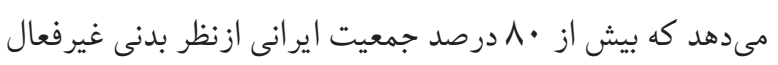

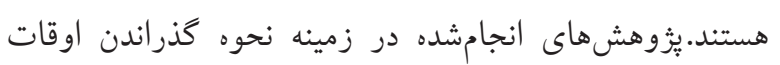

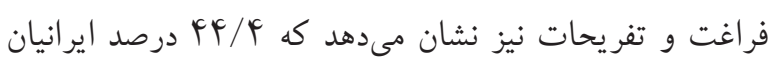

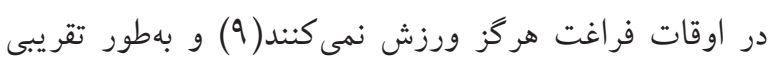

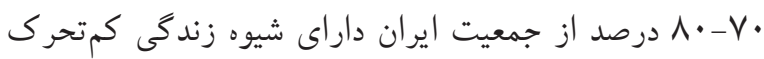

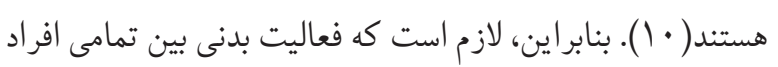
ازجمله جوانان افزايش يابد. امروزه بيشتر مشاغل بدون تحرك (نشسته) هستند. فعاليت

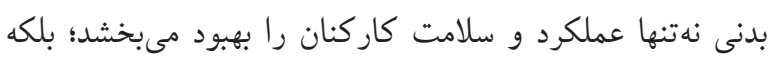
باعث افزايش توليد، كاهش آسيبديدگى، ايجاد روحيه همكارى، افزايش ارتباطات و رضايت شغلى مىشود(9). منافع و موانع

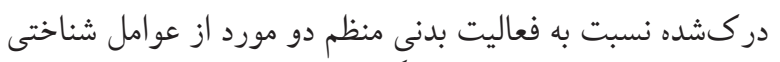


بافتهه جدول ا ويثگى هاى جمعيتشناختى جامعهمورديثوهش رانشان مىدهد. جدول (. مشخصات جمعيتشناختى افر ادموردمطالعه (تعداد V I I ا نفر)

\begin{tabular}{|c|c|c|c|}
\hline \multicolumn{2}{|c|}{ موارد } & \multirow{2}{*}{ تعداد } & \multirow{2}{*}{ درصد } \\
\hline & زن & & \\
\hline جسمي & مرد مرد & 01 & er/s \\
\hline \multirow{2}{*}{ وضعيت تأهل } & همسر دار & $\wedge$ & $V \Delta / r$ \\
\hline & بدون همسر & rq & $r F / \Lambda$ \\
\hline \multirow{6}{*}{ نوع استخدام } & رسمى & ro & $r \cdot / r$ \\
\hline & ييمانى & r. & $\mu F / \Delta$ \\
\hline & شبه بِيمانى & 1. & N/s \\
\hline & شر كتى & If & $\mid r / 1$ \\
\hline & يزشك خانواده & 1. & $1 / 4$ \\
\hline & طرحى & v & $9 /$. \\
\hline \multirow{6}{*}{ مقطع تحصيلى } & ابتدايى & $\Delta$ & $r / r$ \\
\hline & راهنمايى & $r q$ & $r \cdot 10$ \\
\hline & دييلم & $r q$ & $r \xi / \Lambda$ \\
\hline & كاردانى & $r r$ & $1 N / \Lambda$ \\
\hline & كارشناسى & $r r$ & $r V / F$ \\
\hline & دكترا & 0 & $r / r$ \\
\hline
\end{tabular}

در ميان جامعه مورديُزوهش MF/T درصد كارمندان داراى

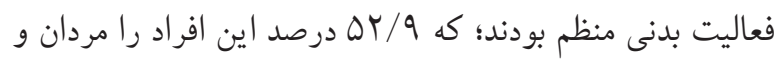

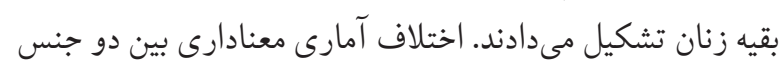

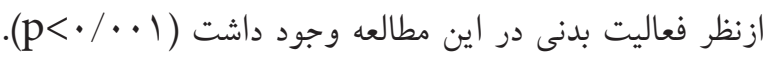

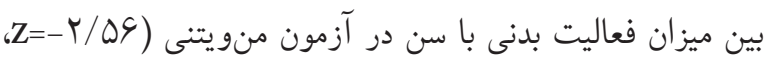

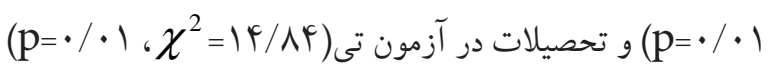

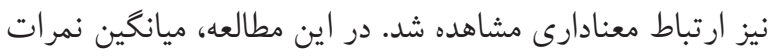

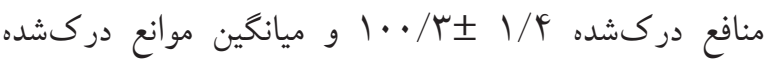

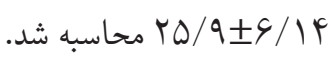

زبان فارسى و انتخاب معادلهاى فارسى دوباره آن را به انخليسى بركرداند و موارد اندكى كه تفاوت وجود داشت به تعابير رايجتر

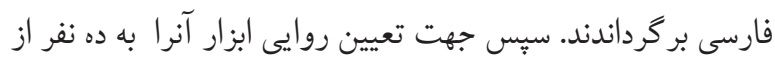

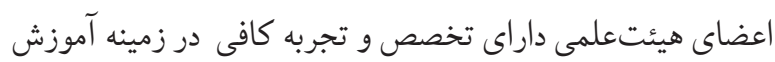

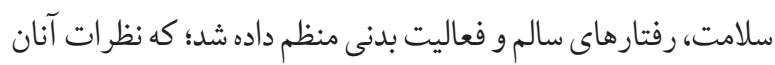
در خصوص يرسشنامه اعمال شد. جهت تعيين پايايى يرسشنامه منافع

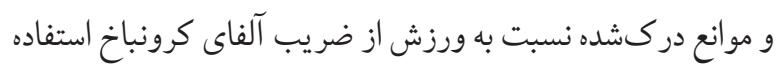

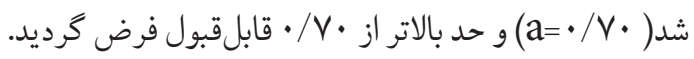

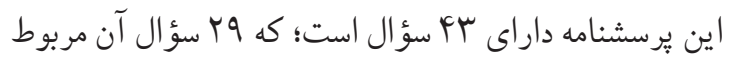

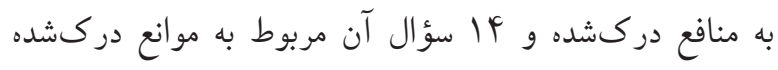

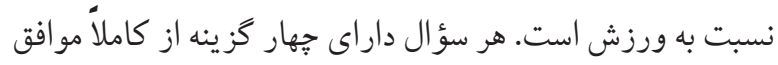

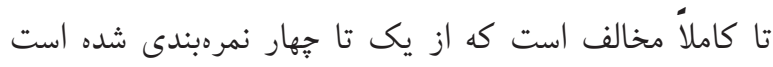

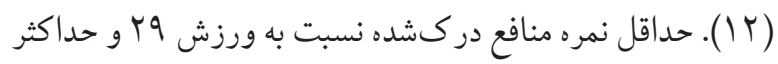

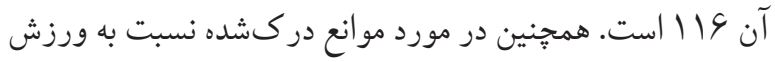

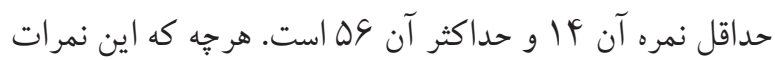

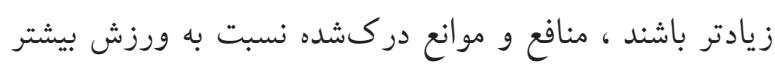

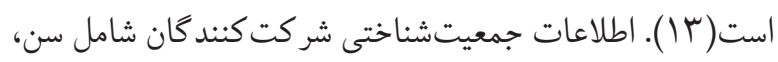
جنس، وضعيت تأهل، مقطع تحصيلى و وضعيت اشتغال بود.

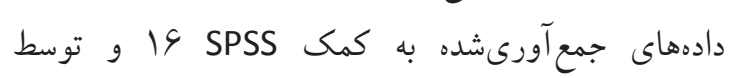
آمار توصيفى (تعيين ميانخين و انحرافمعيار) و آمار تحليلى

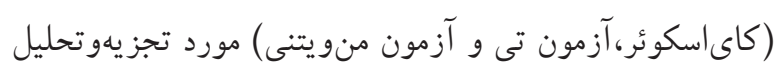

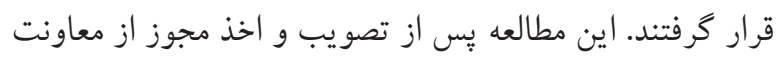

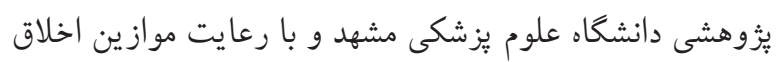
يُزوهش در تمامى مراحل اجرا شد.

جدول r. مقايسه موانع و منافع درك شده در جامعه مورديثوهش برحسب جنس و فعاليت بدنى منظم

\begin{tabular}{|c|c|c|c|c|c|c|c|c|c|c|}
\hline \multirow{3}{*}{ سازه } & \multicolumn{4}{|c|}{ جنسيت } & \multirow{3}{*}{ نتيجه آزمون تى مستقل } & \multicolumn{4}{|c|}{ فعاليت بدنى منظم } & \multirow{3}{*}{ تيجه آزمون تى } \\
\hline & \multicolumn{2}{|c|}{ زن } & \multicolumn{2}{|c|}{ مرد } & & \multicolumn{2}{|c|}{ دارد } & \multicolumn{2}{|r|}{ ن } & \\
\hline & ميانغين & انحر افمعيار & ميانگين & انحرافمعيار & & ميانگين & انحرافمعيار & ميانگين & انحرافمعيار & \\
\hline موانع در كشده & $r \Delta / q$ & $\Delta / \Delta$ & $r \Delta / \Lambda$ & $9 / 9$ & $\begin{array}{l}\mathrm{P}=. / 9 Y \Lambda \\
\mathrm{t}=-. / .9\end{array}$ & $r F / 1$ & $V / r$ & $r s / \Lambda$ & $\Delta / r$ & $\begin{array}{l}\mathrm{P}=\cdot / \cdot r F \\
\mathrm{t}=-r / r \Lambda\end{array}$ \\
\hline منافع درك شده & 1 & $11 / \mathrm{V}$ & 1 & $19 / 0$ & $\begin{array}{l}\cdot / \lambda \cdot=P \\
\cdot / F^{k}=t\end{array}$ & $1 / .1$ & $19 / 09$ & $99 / \mathrm{V}$ & $1 \% / 0$ & $\begin{array}{l}\cdot / \Delta \Lambda=P \\
\cdot / \Delta F V=t\end{array}$ \\
\hline
\end{tabular}


كارمندانى كه فعاليت بدنى منظم داشتند و كارمندانى كه فعاليت

بدنى منظم نداشتند اختلاف آمارى معنادارى مشاهده نشد. يافتهاى اين مطالعه همبستخى معكوس و م معنادارى

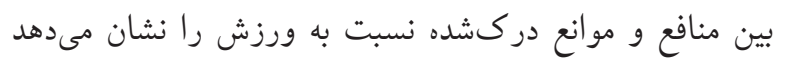
(r=-•/rqT $\mathrm{p}<\cdot / \cdot$ ) l)

جدول شماره Y ميانكين و انحرافمعيار منافع و موانع دركشده نسبت به ورزش را در دو جنس و در دو گروه داراى فعاليت بدنى منظم و بدون فعاليت بدنى منظم نشان مىدهد موانع

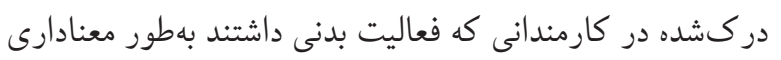
بيشتر بود، در مورد منافع دركشده نسبت به ورزش، بين

جدول سا: مقايسه منافع و موانع دركشده در بين جامعه مورديثووهش

\begin{tabular}{|c|c|c|c|c|c|c|}
\hline \multirow{3}{*}{ منافع و موانع دركشده } & & \multicolumn{4}{|c|}{ انجام فعاليت بدنى منظم } & \multirow{3}{*}{ 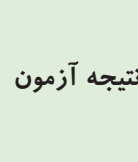 } \\
\hline & & \multicolumn{2}{|c|}{ بلى } & \multicolumn{2}{|c|}{ خير } & \\
\hline & & تعداد & درصد & تعداد & درصد & \\
\hline \multirow{2}{*}{ مكانهاى ورزشى خيلى دورند (موانع دركشده) } & 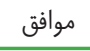 & rl & $\mid N /$ & $\Delta V$ & $r q /$. & \multirow{2}{*}{$\begin{array}{l}\mathrm{p}=\cdot / \cdot 1 \\
\chi^{2}=19 / 10\end{array}$} \\
\hline & 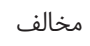 & 19 & $18 /$. & 19 & $19 /$. & \\
\hline \multirow{2}{*}{ ورزش زمان زيادى از روابط خانوادگىام را مى ديرد (موانع } & 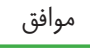 & 49 & $\Delta S /$. & 1 & $\wedge /$ & \multirow{2}{*}{$\begin{array}{l}\mathrm{p}=\cdot / \cdot \mu \mathrm{q} \\
\chi^{2}=\Lambda / \mu r\end{array}$} \\
\hline & مخالف & ro & $r \cdot / \cdot$ & $\Delta$ & $r /$ & \\
\hline \multirow{2}{*}{ خستىى ناشى از ورزش زياد است (موانع درك شده) } & 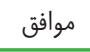 & $\Delta$ & $r /$. & 10 & $1 \% /$ & \multirow{2}{*}{$\begin{array}{l}\mathrm{p}=\cdot / \cdot r \digamma \\
\chi^{2}=9 / F^{\prime}\end{array}$} \\
\hline & 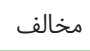 & ro & $r \cdot / \cdot$ & s) & $\Delta r / \Delta$ & \\
\hline \multirow{2}{*}{ دسترسى كم به مكانهاى ورزشى (موانع درك شده) } & 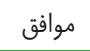 & ro & $r l / \cdot$ & $s q$ & $\Delta \Delta / \cdot$ & \multirow{2}{*}{$\begin{array}{l}\mathrm{p}=\cdot / \cdot 19 \\
\chi^{2}=1 \cdot / r 9\end{array}$} \\
\hline & 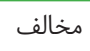 & 10 & $1 \% \%$ & 11 & $9 / \cdot$ & \\
\hline \multirow{2}{*}{ سخت بودن ورزش (موانع دركشده) } & 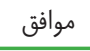 & r & $r / \varphi$ & 1. & $\wedge /$ & \multirow{2}{*}{$\begin{array}{l}\mathrm{p}=\cdot / \cdot r \Delta \\
\chi^{2}=9 / r \mu\end{array}$} \\
\hline & 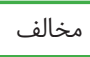 & re & $\mu \mathrm{r}$ & 94 & $\Delta S /$ & \\
\hline \multirow{2}{*}{ دوست داشتن ورزش (فوايد دركشده) } & 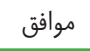 & r. & $\mu r /$. & $V^{F}$ & $s \mu /$. & \multirow{2}{*}{$\begin{array}{l}\mathrm{p}=\cdot / \cdot \Delta \\
\chi^{2}=\Delta / 9 r\end{array}$} \\
\hline & مخالف & . & . & r & $r / \cdot$ & \\
\hline
\end{tabular}

ديخر، شهرستان كلات داراى آب و هواى مناسبتر و موقعيت كوهستانى نسبت به هرمز گان است؛ كه اين امر مىتواند درنتيجه

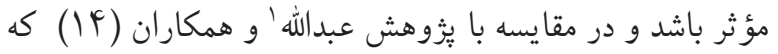

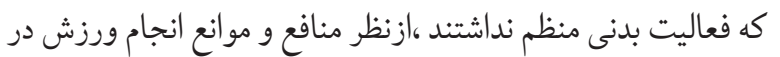
بر روى نمونهاى از دانشجويان در هنگ كنگ انجام شد، نشان داد

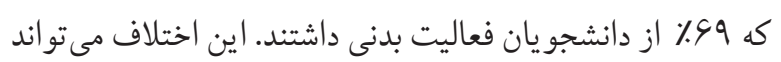
ناشى از متفاوت بودن تعريف فعاليت بدنى در اين تحقيق و وانئن تحقيق مورد اشاره باشد. يافتهاى ديكر اين تحقيق وجود اختلاف آمارى معنادار

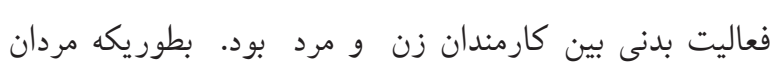

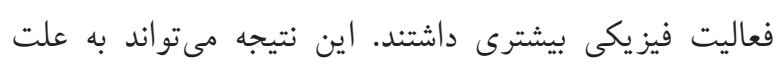

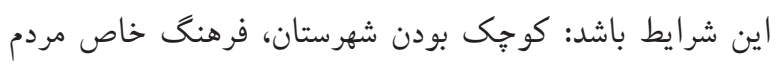
منطقه، وجود ناكافى امكانات ورزشى و آزادتر بودن مردان 1. Abdullah 


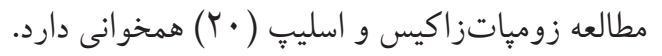
در اين يزوهش، ميانكين نمرات منافع و موانع بين زنان و

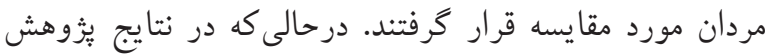

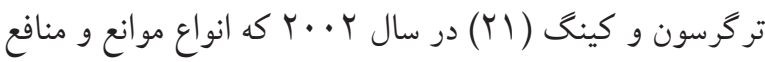
از ديدكاه يسر و دختر موردبررسى قرار دادند، نشان داده شد كه دختران مهمترين منفعت ورزش را تناسب اندام و پِران مهمترين منفعت ورزش را تقويت عضلات مىدانستند. اين يُّوهش مهم ترين مانع ورزش براى دختران را نداشتن وقت كافى

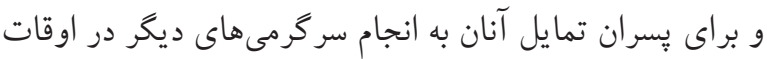

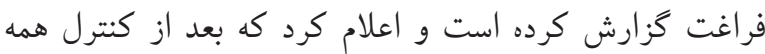
عوامل تأثير گذار بر ورزش، عامل جنس موجب تفاوت فرد فاحشى بين بسران و دختران ازنظر اظهار موانع و منافع دركشده فعاليت بدنى منظم شد. ولى در اين يُزوهش مردان بيشتر ين مانع در انجام

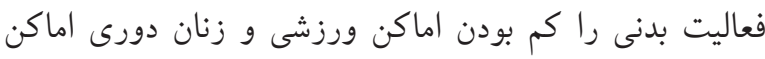

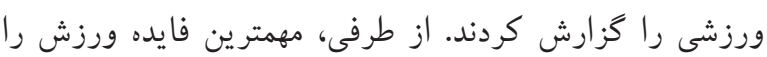
مردان افزايش تحمل بدن و زنان بهبود وضعيت بدنى قيد نمودهاند.

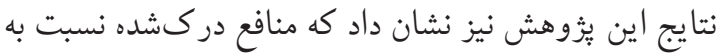

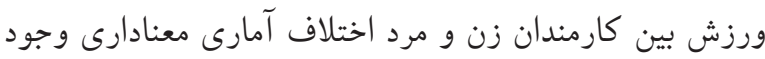

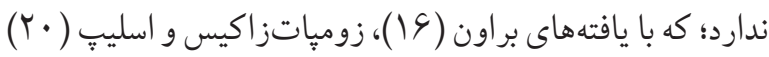

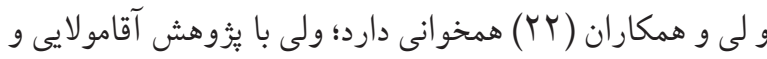
همكاران (IF) كه موانع دركشده نسبت به ورزش را در يسران بيشتر دانست مغايرت دارد. در اين يُزوهش همبستكى متوسط معكوسى بين منافع و موانع دركشده نسبت به ورزش مشاهده

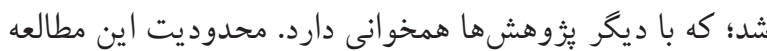
بررسى تنها دو سازه از الكوى اعتقاد بهداشتى بود. نتيجه گَيرى: نتايج اين يُزوهش نشان داد كه درك موانعى نظير

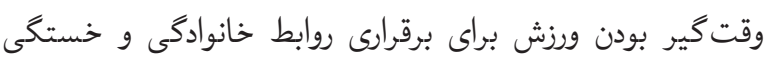
ناشى از وززش مانع از انجام فعاليت بدنى و عواملى جون دوست برت داشتن فعاليت بدنى و كمك به كاهش استرس باعث تقويت

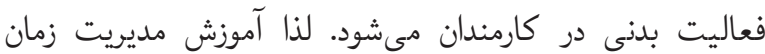
براى انجام فعاليت بدنى منظم و آموزش فوايد و اثرات ورزش به به مدردي
براى ورزش در اماكن عمومى. نتايج ساير يُزوهشها حاكى از اين است كه ميزان فعاليت بدنى در دانشجويان پِّر بيشتر از

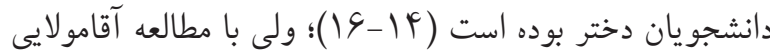
و همكاران (IF) كه اختلاف آمارى معنادارى در ميزان فعاليت بدنى دو جنس نيافتند، مطابقت ندارد(IV). نتايج يثروهش مئراي وانبوتمر و فردلاند(IV) نشان داد كه دانشجويان پِر در مقايسه با دانشجو يان دختر علاقهمندى كمترى به فعاليتهاى بدنى ارتقاء دهنده سطح سلامت هستند. ميانگين نمره منافع دركشده در يُزوهش حاضر، كمتر از

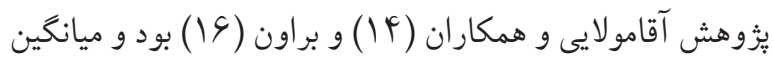

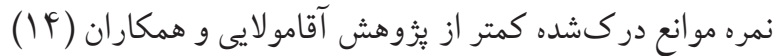

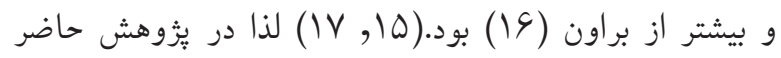
موانع دركشده توسط كارمندان خيلى بيشتر از منافع دركشده بر برد

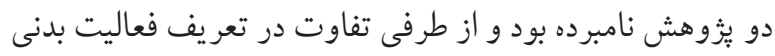
در مطالعات گوناگون مى تواند به نتايج مختلفى ختم شود.

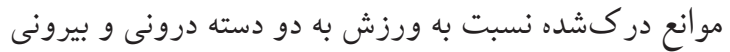

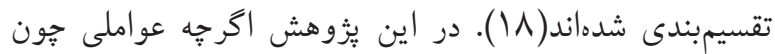

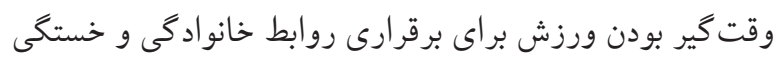

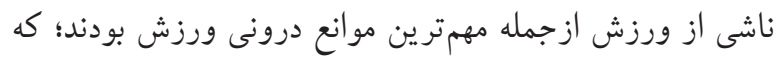

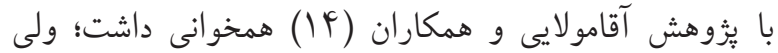
عمدهترين موانع دركشده بيرونى يا به عبارتى موانع محيطى

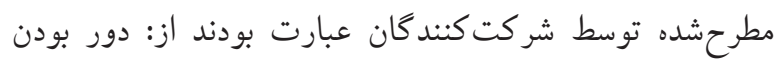
مكانهاى ورزشى، كمبود مكانهاى ورزشى و نبود امكان استفاده

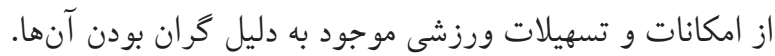
اين موارد مى تواند موردتوجه برنامهريزان قرار كيرد. با توجه به اينكه اكثر يُوهشها به مو موانع محيطى در ارتباط با ورزش ازجمله

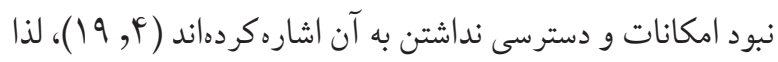
ييشبينى لازم در خصوص تدارك امكانات و تسهيلات مناسب ورزشى براى كارمندان مىتواند به ارتقاى فعاليت بدنى منظم

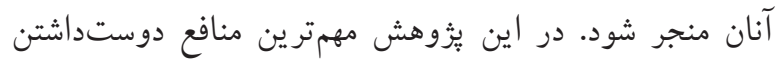

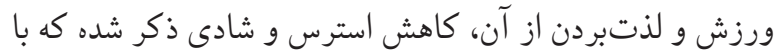




$$
\begin{aligned}
& \text { همجنين بيشنهاد مىشود كه حمايت اجتماعى از كارمندان } \\
& \text { جهت افزايش فعاليت بدنى در آنها افزايش يابد. تشويق } \\
& \text { كارمندان توسط كارفرمايان به ورزش و داشتن فعاليت بدنى } \\
& \text { منظم يك راه آن است. }
\end{aligned}
$$

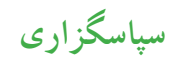

$$
\begin{aligned}
& \text { نويسندكان بر خود لازم مىدانند از مدير محترم و كاركنان شبكه } \\
& \text { بهداشت و درمان شهرستان كلات و ديخر عزيزانى كه به انجام اين } \\
& \text { يثوهش يارى رساندند، تشكر و قدردانى نمايند. }
\end{aligned}
$$

\section{References:}

1. Troped PJ, Saunders RP, Pate RR, Reininger B, Ureda JR, Thompson SJ. Associations between self-reported and objective physical environmental factors and use of a community rail-trail. Preventive medicine. 2001;32(2):191200.

2. Sallis JF, Owen N, Fisher EB. Ecological models of health behavior. Health behavior and health education: Theory, research, and practice. 2008;4:465-86.

3. Aghamolaei T TS, Hassani L. Exercise Self-efficacy, Exercise Perceived Benefits and Barriers among Students in Hormozgan University of Medical Sciences. Iranian Journal of Epidemiology. 2009;4(3, 4).

4. Thøgersen-Ntoumani C. An ecological model of predictors of stages of change for physical activity in Greek older adults. Scandinavian journal of medicine \& science in sports. 2009;19(2):286-96.

5. Martin KR, Schoster B, Shreffler JH, Meier A, Callahan LF. Perceived Barriers to Physical Activity Among North Carolinians With Arthritis: Findings From. NC Med J. 2007;68(6).

6. Petersen PE. The World Oral Health Report 2003: continuous improvement of oral health in the 21st century-the approach of the WHO Global Oral Health Programme. Community Dentistry and oral epidemiology. 2003;31(s1):3-24.

7. Tehrani Hadi,Gholian-Aval Mahdi, Hasani-kabootarkhani Marzieh, Peyman Nooshin, Vahedian-Shahroodi Mohammad. The impact of new communications technology on promoting women's physical activity. PAYESH. 2016;15(3):293-300.

8. Sharifirad G, Mohebbi S, Matlabi M. The relationship of physical activity in middle age and cardiovascular problems in old age in retired people in Isfahan, 2006. The Horizon of Medical Sciences. 2007;13(2):57-63.

$$
\begin{aligned}
& \text { كارمندان، بهويثه كارمندان با تحصيلات كمتر مىتواند تا حدودى } \\
& \text { مؤثر واقع شود. با توجه به اينكه هر دو عامل فردى و محيطى } \\
& \text { مى تواند سهم خود را در انجام نشدن فعاليت بدنى منظم ايفا نمايد، } \\
& \text { بايد در برنامهريزىهاى آينده موردتوجه مسئولين بهداشتى قرار كيرد. } \\
& \text { توجه به نتايج اين يثوهش، جهت افزايش فعاليت بدنى در كارمندان } \\
& \text { بايستى موانع دركشده نسبت به ورزش، بهويثه موانع بين فردى } \\
& \text { و محيطى، كاهش يابد. جهت ارتقاى سطح فعاليت بدنى بايد } \\
& \text { امكانات محيطهاى ورزشى بهبود يافته و همجٍنين جهت استفاده } \\
& \text { كارمندان بهويزه كارمندان زن محيطهاى مناسب فراهم كردد. }
\end{aligned}
$$

9. Manuchehr M. knowledge, Attitude and Practice Social-Cultural behavior in Iran. Persian Published First. 2000:190-1.

10. SHEYKH ALESLAM ROBABEH MA, MOHAMMAD K, Vaseghi S. Non communicable disease risk factors in Iran. Asia Pacific journal of clinical nutrition. 2004;13(3):100-.

11. . Iranian Journal of Epidemiology. 2009;4(3, 4).

12. Sechrist KR, Walker SN, Pender NJ. Development and psychometric evaluation of the exercise benefits/barriers scale. Research in Nursing \& Health. 1987;10(6):357-65.

13. Aghamolaei t TS, Hassani L,Zare Shahram. Physical activity and stages of change: application of the Trans Theoretical Model. Payesh. 2008.

14. Grubbs L, Carter J. The relationship of perceived benefits and barriers to reported exercise behaviors in college undergraduates. Family \& Community Health. 2002;25(2):76.

15. Brown SA. Measuring perceived benefits and perceived barriers for physical activity. American journal of health behavior. 2005;29(2):107-16.

16. Abdullah A, Wong C, Yam H, Fielding R. Factors related to non-participation in physical activity among the students in Hong Kong. International journal of sports medicine. 2005;26(07):611-5.

17. Aghamolaei T, Tavafian S, Hassani L. Exercise Self-efficacy, Exercise Perceived Benefits and Barriers among Students in Hormozgan University of Medical Sciences. Iranian Journal of Epidemiology. 2009;4(3-4).

18. Gyurcsik NC, Spink KS, Bray SR, Chad K, Kwan M. An ecologically based examination of barriers to physical activity in students from grade seven through first-year university. Journal of Adolescent Health. 2006;38(6):704-11.

19. Hohepa M, Schofield G, Kolt GS. Physical activity: what do high school students think? Journal of Adolescent Health. 2006;39(3):328-36. 